\title{
Evaluating the effects of leaf characteristics on spectral signatures of savannah woody species on remotely sensed imagery
}

\author{
Chris Munyati ${ }^{1}$, Lebo Eneth Malomane ${ }^{1}$, Oupa Ermos Malahlela ${ }^{2}$ \\ ${ }^{1}$ Department of Geography and Environmental Science, North-West University, Mmabatho, \\ South Africa, chrismunyati@yahoo.co.uk \\ ${ }^{2}$ Earth Observation division, South African National Space Agency, Pretoria, South Africa
}

DOI: http://dx.doi.org/10.4314/sajg.v7i3.9

\begin{abstract}
Woody species on savannahs provide nutrition to wildlife and livestock ungulates. Understanding of woody leaf reflectance would benefit the application of remote sensing in analysis of these rangelands. This study sought to establish the influence of the leaf characteristics of size (leaf form) and chlorophyll content on the spectral reflectance characteristics of savannah woody species. The ability of optical remotely-sensed imagery to identify these two leaf characteristics and use them to determine the woody content of savannahs was then assessed. Two species that represented narrow leaf and broad leaf savannah woody species were studied: Acacia tortilis (renamed Vachellia tortilis) and Ziziphus mucronata, respectively. Forty seven woody individuals representing these species were sampled in north-western South Africa. Chlorophyll content, leaf area index (LAI) and spectral reflectance were determined in-situ using a chlorophyll meter, a canopy analyser and spectroradiometer, respectively. A SPOT 6 NAOMI image acquired at a time of year when grass reflectance was excluded from the spectral signature of non-senescent vegetation was used. The image data were converted to reflectance (\%), and the green and near infrared (NIR) reflectance of the field-sampled trees on the image were correlated with the in-situ data. The results showed that the woody species differed significantly in their chlorophyll content and green reflectance, but only the NIR reflectance of the broad leaf species correlated strongly with a leaf characteristic, LAI. From the results it is concluded that LAI is the more reliable leaf characteristic for analysing the characteristics of savannahs in terms of woody content.
\end{abstract}

\section{Introduction}

Woody species provide nutrition to a diversity of wildlife and livestock browsers on savannah rangelands (Grunow, 1980; Hempson et al., 2015). Improved understanding of the spectral reflectance of particular woody species would allow rangeland managers to identify the woody species in imagery, and then assess the relative abundance and state of the woody species. Therefore, such assessments are of importance both to nature conservation and the game and ranch industry. 
In theory the reflectance of electromagnetic energy by plants is affected by a number of factors, primarily leaf pigments (anthocyanin, carotenoids, chlorophyll, xanthophyll), disease, moisture, nutrient content, and leaf thickness (Ceccato et al., 2001; Knipling, 1970; Lillesand et al., 2015; Peñuelas et al., 1993; Petisco et al., 2005). In the visible spectral region chlorophyll strongly absorbs in the blue (400-500nm) and red (600-700nm), with some reflectance of green energy (500$600 \mathrm{~nm})$. From the red-edge $(680-750 \mathrm{~nm}$; Horler et al., 1983) the spectral reflectance increases considerably in the near infrared (NIR) region $(\approx 780-1200 \mathrm{~nm})$, compared to that in the visible. The main factor that affects reflectance in this region is the internal cellular arrangement in the leaf, which makes reflectance vary per plant species. At the level of the plant canopy, in theory the reflectance is similar to that of the leaf, but it is modified by the non-uniformity of incident solar radiation, plant structures, leaf area, shadows, and canopy background reflectance (Knipling, 1970).

Whereas such factors that influence the spectral reflectance of plants are well established in theory and for non-savannah biome species (e.g. Baldini et al., 1997; Gitelson et al., 2003; Sims \& Gamon, 2002), the specific nature of their influence on savannah woody species is perhaps less well investigated. In temperate plant species Sims \& Gamon (2002) established that the presence of other pigments did not significantly affect estimation of chlorophyll from spectral reflectance, which suggests that reflectance in the visible region can be indicative of chlorophyll content. Working with temperate woody species Gitelson et al. (2003) showed that reciprocal reflectance $(\mathrm{R}<)^{-1}$ in the $520-550 \mathrm{~nm}$ and $695-705 \mathrm{~nm}$ spectral ranges related closely to the total chlorophyll content in leaves of all species. Munyati et al. (2013) showed that the spectral signatures of four narrow-leaf savannah woody species (Acacia karroo, A. mellifera, A. tortilis, Dichrostachys cinerea) were markedly different in the NIR, but the work did not compare their chlorophyll contents.

In this work the influence of the leaf characteristics of size (leaf form) and chlorophyll content on the spectral reflectance characteristics of a sample of savannah woody species is investigated. The results are placed in the context of abilities to remotely sense the state of the woody species using optical remotely sensed imagery.

\section{Material and methods}

\subsection{Study area}

Sampling of woody species was conducted in savannah areas in north-western South Africa, in Botsalano and Mafikeng Game Reserves (Figure 1). The bulk of the sampling was in Botsalano, with only supplementary work in Mafikeng Game Reserve.

The rain season in the savannahs of South Africa commences in November and ends in April the following year. On average Zeerust, the nearest town to Botsalano Game Reserve, receives about 550-600mm of rainfall a year, while Mafikeng receives slightly less (Mucina \& Rutherford, 2006). Consequently, there are slight differences in the woody species composition of the study sites, with a higher proportion of broad leaf species in Botsalano than in Mafikeng Game Reserve. The 
vegetation in the study areas is characterised by Mucina \& Rutherford (2006) as Mafikeng Bushveld (in Mafikeng Game Reserve) and mainly Klerksdorp Thornveld in Botsalano Game Reserve. Both reserves stock a number of grazer and browser ungulate species. The notable tall and large-bodied browser species that can browse tree leaves are giraffe (Giraffa camelopardalis) and kudu (Tragelaphus strepsicero), which can browse summit leaves on short trees or leaves in lower sections of tall tree canopies.
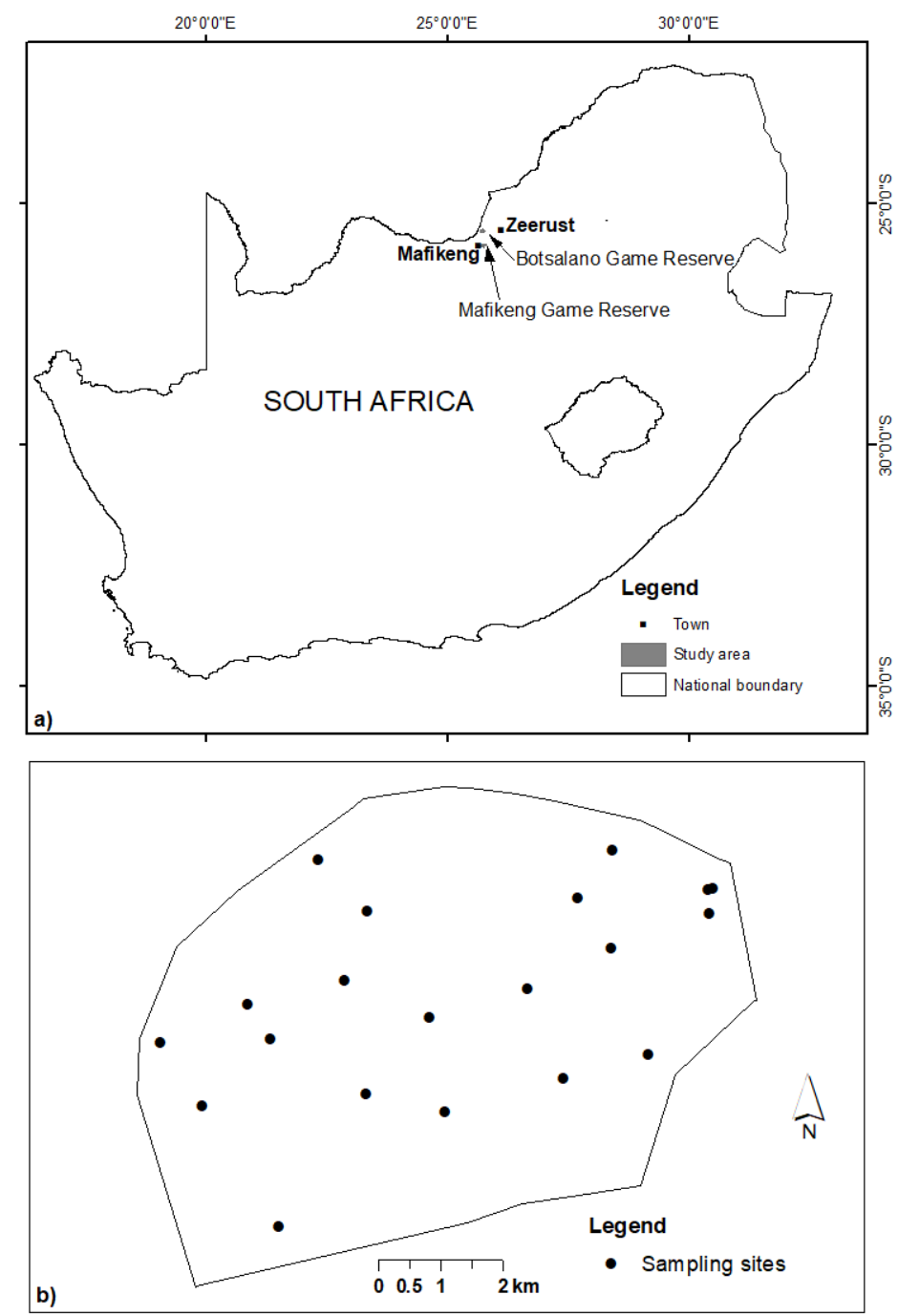

Figure 1. Location of the study areas. In (b) the distribution of tree sampling in the Botsalano study site is illustrated

\subsection{Field sampling}

Two savannah woody species were selected to represent the main leaf forms of the woody species in the area: broad leaf and narrow leaf. The species were Acacia tortilis (common name: umbrella thorn) and Ziziphus mucronata (common name: buffalo thorn). In 2005 the XVII International Botanical Congress (IBC) voted to rename the Acacia plant genus as Vachellia under the International Code of Botanical Nomenclature. Given that the change has been controversial and opposed (Thiele et al., 2011), in this paper the name Acacia by which this woody genus was more widely known is retained. The two selected woody species were widespread in the Botsalano study 
site, and are consumed by browsers such as giraffe. A. tortilis has a pinnate compound leaf and, therefore, represented the narrow leaf woody species. Z. mucronata on the other hand has a simple, and comparatively larger, leaf form (Figure 2).

Sampling in the study sites was conducted from $16^{\text {th }}$ to $20^{\text {th }}$ April 2018. As this period was in the transition between summer and winter, there was only a limited window within which to collect data on reflectance from the woody species leaves. This limited the number of samples because the data needed to be collected when all species were in the same leaf condition, considering that some were entering the autumn leaf fall period. Considering this factor and logistical limitations, data from a total of 47 trees were collected in the two study sites. In the Botsalano study site the sampling sites were well distributed (Figure 1b), representing trees in valley, crest and mid-slope positions. In the Mafikeng site the two species were limited in distribution, perhaps due to the combination of the arable farming land use history and the clay soil in the southern sector. Therefore, data from only 11 trees were collected in Mafikeng Game Reserve. The trees that were selected all had crown diameters larger than $5 \mathrm{~m}$, large enough to register as pixels on imagery of the newer sensors with high spatial resolution (finer than $10 \mathrm{~m}$ ). The UTM coordinates of the location of each tree were obtained using a Garmin eTrex ${ }^{\circledR}$ Global Positioning System (GPS). At each sampling site a $Z$. mucronata and an A. tortilis tree were sought, in close proximity (e.g. see Figure 2), to minimise differences due to soil substrate. Leaves that visually manifested vigour and lacked infections or mechanical damage were targeted for data collection.

From each tree, data on chlorophyll concentration in a number of leaves were collected in-situ using a hand-held CCM-300 chlorophyll meter ${ }^{\circledR}$. The leaves were selected from about $1.5 \mathrm{~m}$ above ground (i.e. breast height), both in the northern and southern sections of the canopy and widely spaced apart. The breast height was used because observations in the field indicated that leaves in low sections of the canopy manifested signs of abrasion damage. Chlorophyll concentration readings from four leaves per individual plant were taken and then the average was recorded. Soon after obtaining the chlorophyll concentration data, in-situ reflectance (i.e. without cutting the leaves off the branches) from the same leaves used was determined using a Spectral Evolution PS-3500® portable spectroradiometer (sensing in the $350-2500 \mathrm{~nm}$ range, at $3 \mathrm{~nm}$ resolution) by contact (i.e. using a leaf clip). From the spectral reflectance graphs obtained the reflectance (\%) value in the green (500-600nm) and NIR (800-1200nm) were obtained and recorded.

For each tree sampled the leaf area index (LAI) was also obtained, using a hand-held LiCOR Plant Canopy Analyser ${ }^{\circledR}$. The instrument measures LAI of green canopies from single vantage points, using sensors that simultaneously measure light intensities in the blue spectral range in concentric Field of Views (FOVs). It requires below canopy and canopy-free readings that are then averaged to calculate the canopy gap fraction, which represents the probability of light penetration. Gap fraction values are then converted to contact frequency values that are used for further analysis (LI-COR Inc., 1992). This instrument required full illumination conditions. During the fieldwork in the Mafikeng site, overcast weather prevented the collection of LAI data. Therefore, only 36 LAI measurements on trees in the Botsalano site were obtained. 
South African Journal of Geomatics, Vol. 7. No. 3, November 2018

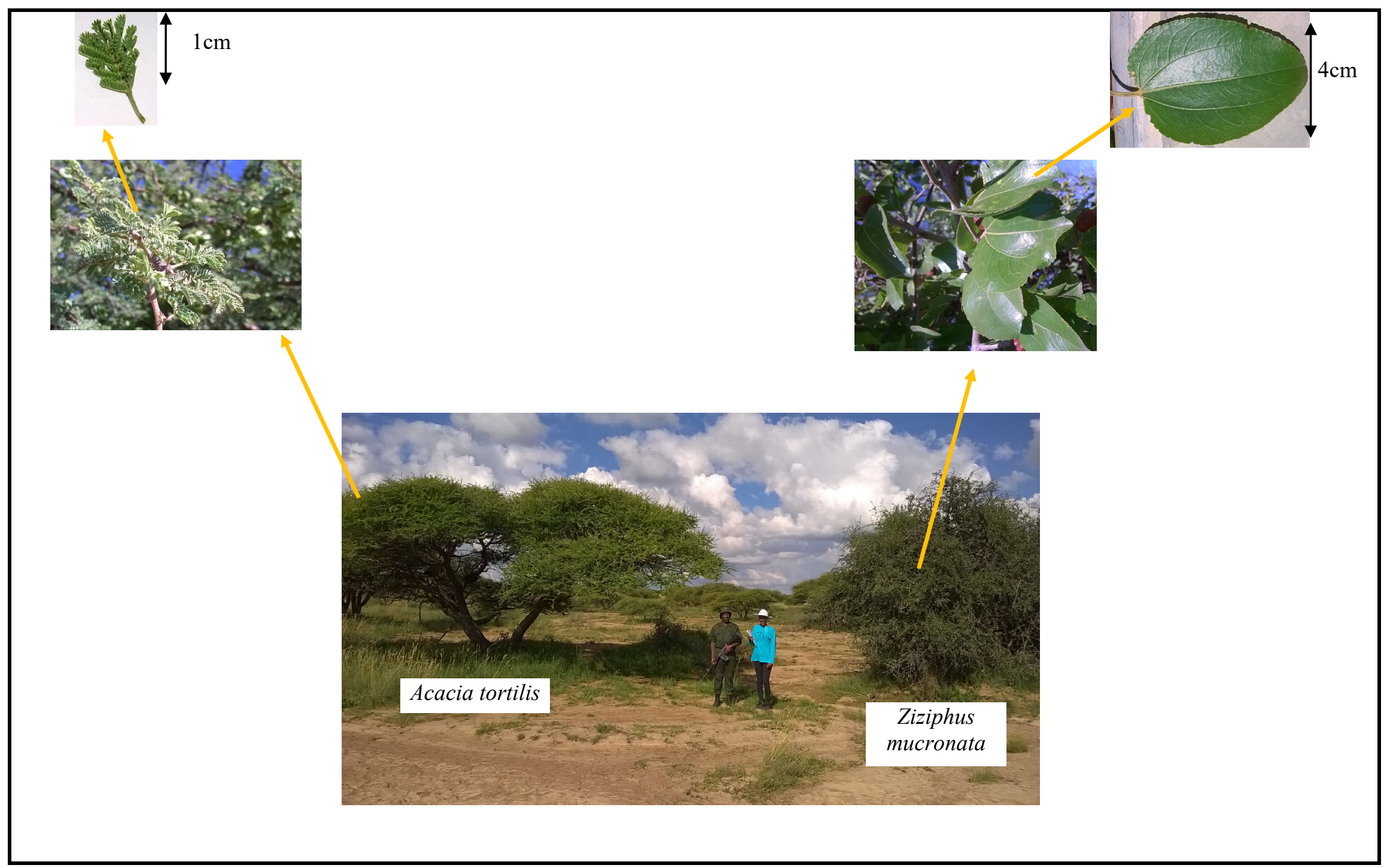

Figure 2. Pictorial illustration of the physical and leaf form (insets) characteristics of the two woody species sampled 


\subsection{Analysis of Leaf Reflectance Data in Relation to Optical Imagery}

The in-situ tree leaf reflectance data were related to optical imagery using SPOT 6 NAOMI imagery, which were readily available from the South African National Space Agency (SANSA) at the time of the study. The SPOT 6 NAOMI sensor collects reflectance data in four multispectral bands: blue $(455-525 \mathrm{~nm})$, green $(530-590 \mathrm{~nm})$, red $(625-695 \mathrm{~nm})$ and NIR $(760-890 \mathrm{~nm})$, at $6 \mathrm{~m}$ spatial resolution. The ideal date of the image would have been the date of data collection, and when the grass is in senescence. Due to the slightly delayed end of the rain season in 2018, during the period of the field work the grass had not yet entered senescence. Consequently, an image from November 2017 when the rains were just starting and the grass was still in senescence was used. In November the tree leaves are at full size, their vigour equivalent to that in April.

The SPOT 6 NAOMI images was corrected for haze using a built in haze removal module in ERDAS imagine $2018 \AA$. Thereafter the image digital number $(\mathrm{DN})$ data were converted to atsensor radiance $\left(L_{\lambda}\right)$ using Equation [1], and then to top-of-atmosphere (TOA) reflectance $(\rho, \%)$ using Equation [2] (Clark et al., 2010):

$$
\begin{aligned}
& \text { Radiance }\left(L_{\lambda}\right)=\frac{D N}{G}+B \\
& \rho=\frac{\pi L_{\lambda} d^{2}}{\operatorname{Esun}_{\lambda} \cos \theta_{s}}
\end{aligned}
$$

where:

$L_{\lambda}=$ at-sensor radiance $\left(\mathrm{Wm}^{-2} \mathrm{sr}^{-1} \mu \mathrm{m}^{-1}\right)$,

$D N=$ digital number,

$\mathrm{G}=$ band absolute calibration gain $\left(1 / \mathrm{W}^{*} \mathrm{~m}^{2 *} \mathrm{sr}^{*} \mu \mathrm{m}\right)$,

$B=$ band offset value,

$\rho=$ reflectance,

$d=$ date corrected earth-sun distance (astronomical units),

$E s u n_{\lambda}=$ SPOT sensor- and band-specific equivalent solar irradiance $\left(\mathrm{Wm}^{-2} \mu \mathrm{m}^{-1}\right)$,

$\theta_{s}=$ solar zenith angle.

G, B, Esun $\lambda$ and $\theta_{s}$ values were obtained from the image metadata.

The image was obtained at the ortho pre-processing level, with geographic coordinates. Since the coordinates of the field data sampling sites were recorded in the UTM system (in metres), the reflectance image was geometrically corrected to the UTM projection, using the ground control points (GCP) module in ERDAS Imagine 2018®. Nearest neighbour resampling was employed during the geometric correction, and the rectification error (root mean square error, RMSE) was less than one pixel. The trees whose LAI, chlorophyll and in-situ reflectance data were obtained in the field could then be located on the high spatial resolution reflectance image (Figure 3), so their $\rho$ (\%) values in the green (band 2) and NIR (band 4) were obtained and correlated. Reflectance in the red spectral range was not analysed due to absorption of red energy by chlorophyll. For the in-situ 
reflectance data the green and NIR reflectance data were also correlated. The differences in reflectance between $Z$. mucronata and $A$. tortilis were assessed for statistical difference.

\section{Results}

Table 1 summarises statistical analysis results for the two woody species studied. The two differed in their chlorophyll contents and in terms of in-situ green and NIR reflectance. $Z$. mucronata $\left(\right.$ mean $\left.=341.0 \mathrm{mgm}^{-2}\right)$ had significantly higher chlorophyll content $(t=5.912, p<0.001)$ than A. tortilis $\left(\right.$ mean $\left.=303.1 \mathrm{mgm}^{-2}\right)$. However, A. tortilis had significantly higher $(t=7.979, p<$ $0.001)$ green reflectance $($ mean $=14.8 \%)$ than $Z$. mucronata $($ mean $=10.1 \%)$. Collectively for all trees sampled chlorophyll concentration only marginally explained the variations in in-situ reflectance of green and NIR energy, though the relationship was slightly stronger with respect to the broad leaf $Z$. Mucronata (Figure 4).

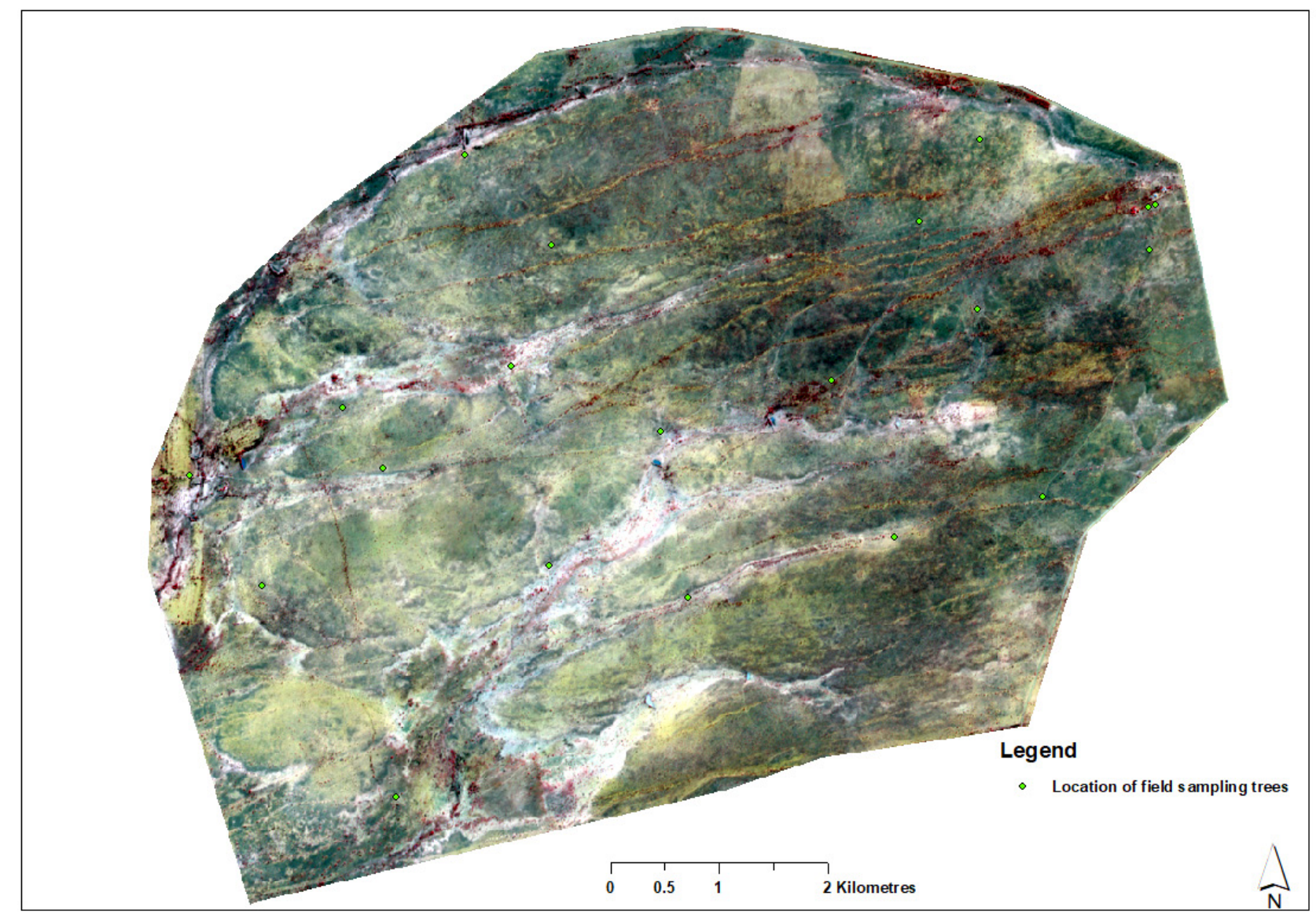

Figure 3. The reflectance image of the Botsalano Game Reserve study site (RGB:432), with the locations of the trees whose chlorophyll, LAI and reflectance were determined in-situ in the field. The location symbols are not to scale (are exaggerated for visibility)

The two species did not differ significantly in NIR reflectance either in terms of in-situ reflectance determined by the spectroradiometer $(t=0.734, p>0.05)$ or above canopy reflectance captured by the SPOT 6 NAOMI sensor $(t=0.541, p>0.05)$. However, the broad leaf $Z$. 
mucronata had higher in-situ NIR reflectance (mean $=43.9 \%$ ) than the narrow leaf $A$. tortilis (mean $=42.9 \%$ ). For Z. mucronata LAI was strongly correlated with SPOT 6 NAOMI reflectance in the NIR $(r=0.458, p<0.05)$ but less so with the green reflectance $(r=0.321, p>0.05)$. The narrow leaf $A$. tortilis yielded positive correlation between LAI and reflectance, but it was statistically not significant both in the NIR $(r=0.291, p>0.05)$ and the green $(r=0.199, p>0.05)$ SPOT 6 NAOMI bands.

Table 1. Summary of statistical comparison of selected attributes of the species studied

Mean chlorophyll concentration

Z. mucronata: mean $=341.0 \mathrm{mgm}^{-2}$

A. tortilis: mean $=303.1 \mathrm{mgm}^{-2}$

$t=5.912$

$<0.001$

Spectroradiometer in-situ green reflectance:

Z. mucronata : mean $=10.1 \%$

A. tortilis: mean $=14.8 \%$

$t=7.979$

$<0.001$

Spectroradiometer in-situ NIR reflectance:

Z. mucronata : mean $=43.9 \%$

A. tortilis: mean $=42.9 \%$

$t=0.734$

$>0.05$

Green reflectance on SPOT 6 NAOMI image:

Z. mucronata : mean $=11.5 \%$

A. tortilis: mean $=12.1 \%$

$t=0.687$

$>0.05$

NIR reflectance on SPOT 6 NAOMI image:

Z. mucronata : mean $=19.6 \%$

A. tortilis: mean $=20.3 \%$

$t=0.541$

$>0.05$

LAI:

Z. mucronata : mean $=4.22$

A. tortilis: mean $=3.26$

$t=1.93$

$<0.05$

Correlation LAI versus green reflectance on

Z. mucronata: $\mathrm{r}=0.384 \quad>0.05$

SPOT 6 NAOMI image

A. tortilis: $r=0.321$

$>0.05$

Correlation LAI versus NIR reflectance on

Z. mucronata: $r=0.458$

$<0.05$

A. tortilis: $r=0.291$ $>0.05$ 


\section{Discussion}

The broad leaf $Z$. mucronata had higher chlorophyll concentrations than the narrow leaf $A$. tortilis perhaps as a result of leaf thickness and surface wax. The Z. mucronata leaf is slightly thicker: about $1 \mathrm{~mm}$ thick compared to the less than $1 \mathrm{~mm}$ thickness of the A. tortilis leaf. It also visibly appears to contain more surface wax (Figure 2) compared to the A. tortilis leaf. Both leaf thickness and surface wax can increase the leaf's reflectance in the visible and NIR regions (da Luz \& Crowley, 2007; Sims and Gamon, 2002). The higher NIR and green reflectance on the SPOT 6 NAOMI bands in comparison with the corresponding in-situ reflectance is likely to be due to atmospheric additive effects which were not effectively corrected by the haze reduction algorithm used.

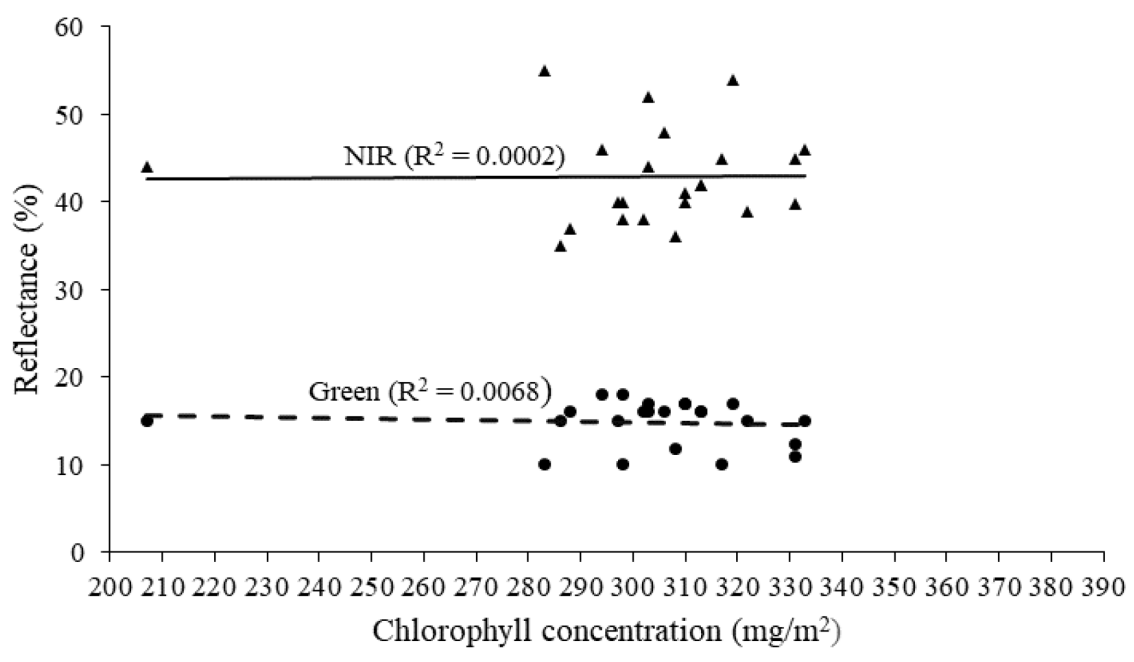

(a) Acacia tortilis

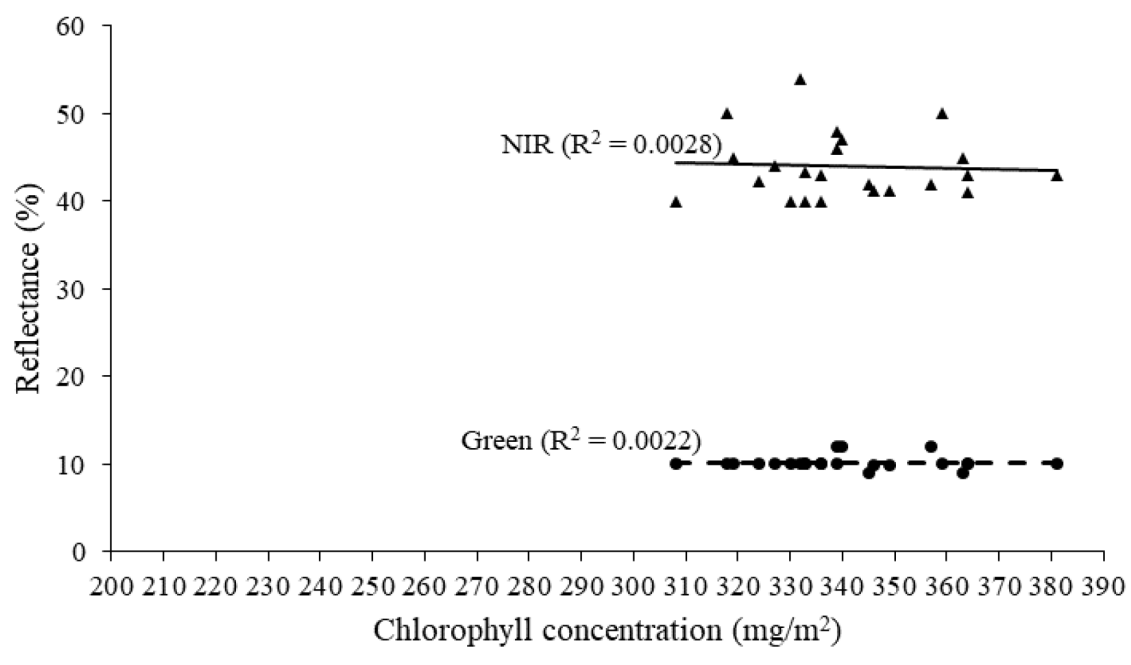

(b) Ziziphus mucronata

Figure 4. Relationship between leaf chlorophyll concentration and spectral reflectance in the green $(500-600 \mathrm{~nm})$ and near infrared (NIR, 800-1200nm) spectral regions. Reflectance data were from the spectroradiometer 
The results suggest that chlorophyll concentrations in leaves of savannah woody species do not influence green reflectance sufficiently strongly to manifest statistically significant differences among woody species. Similar results were obtained by Sánchez-Azofeifa et al. (2009) for tropical rain forest species (lianas versus trees). The in-situ green spectral reflectance measurements (Figure 4) yielded very little variation, which ranged between $10 \%$ and $15 \%$ despite the variations in chlorophyll concentrations. Sims and Gamon (2002) similarly determined little variation in reflectance with increases in chlorophyll concentrations in a temperate deciduous species. This suggests that other leaf pigments influence the reflectance of green energy by savannah woody species. The lack of statistically significant difference between the two species in the above canopy green reflectance captured on the SPOT 6 NAOMI band is perhaps also due to additive effects from canopy background reflectance. Additive effects from canopy background reflectance can be high in narrow leaf species. The large inter-canopy gaps in the narrow leaf species allow reflectance from stem material, background soil and plant litter (Knipling, 1970; Munyati et al., 2013). This could have caused the slightly higher NIR reflectance by the narrow leaf $A$. tortilis whose LAI averaged at 3.26 in comparison with the higher mean LAI of 4.22 in the broad leaf $Z$. mucronata (Table 1). Studies of non-savannah woody vegetation (e.g. Eriksson et al., 2006) have shown that high LAI results in low NIR reflectance from canopy background vegetative material, which qualifies this interpretation. The stem material is more reddish on Z. mucronata (Figure 2), perhaps partly contributing to the lower above canopy green reflectance (captured by the SPOT 6 NAOMI sensor) in comparison with $A$. tortilis (Table 1).

NIR reflectance, on the other hand, appeared to be more related to the leaf characteristics of broad leaf savannah woody species. This is indicated by the slightly stronger and statistically significant relationship between LAI and the above canopy NIR reflectance of the broad leaf $Z$. mucronata captured on the SPOT 6 NAOMI image (Table 1). Therefore, this suggests that the broad leaf species content of savannahs is perhaps easier to assess than is the case with narrow leaf species. LAI is the more reliable leaf characteristic in aid of this analysis, using LAI retrieval algorithms (e.g. Mayr \& Samimi, 2015; Ribeiro et al., 2008). Asner (1998) showed that stem material played a small but significant role in determining canopy reflectance in woody plant canopies, especially those with LAI $<5.0$. The two woody species in this study generally had LAI $<$ 5.0 and, therefore, stem material did play a role in the NIR reflectance, which could explain the lack of significant difference in above canopy NIR reflectance (captured on the SPOT 6 NAOMI image) between the species. In general, however, the LAI values derived from this study are much higher than those determined in-situ by Mayr \& Samimi (2015) in the savannahs of Namibia, due to the larger tree and canopy structures of the woody vegetation at this study's sites. This further indicates the potential role of LAI in indicating woody vegetation content of savannahs.

The results from this study are quite indicative of the spectral reflectance characteristics of savannah woody species as influenced by leaf form. Since sampling was conducted at the end of the rain season, all leaves were at full maturity. Therefore, differences in age of the leaves did not contribute significantly to differences in reflectance. Additionally, differences in leaf moisture 
content were minimised since the study was conducted at the height of the rain season when moisture stress was low. Foliar biochemistry (e.g. lignin, protein content), which can affect spectral reflectance (Asner, 1998; da Luz \& Crowley, 2007), was beyond control in the experimental design in this work. The lack of significant difference in in-situ NIR reflectance between the two species studied is consistent with results by Sánchez-Azofeifa et al. (2009) and Castro-Esau et al. (2004), who obtained no significant difference in NIR reflectance between lianas and trees in tropical forests.

\section{Conclusion}

This study sought to establish the influence of the leaf characteristics of size (leaf form) and chlorophyll content on the spectral reflectance characteristics of savannah woody species. Samples of two woody species that represented the narrow and broad leaf form, respectively, were used for the investigation. The results were placed in the context of abilities to remotely sense the content and state of the woody species using optical remotely sensed imagery. Chlorophyll concentrations were found to influence reflectance only weakly, both from field spectroscopy and on optical satellite imagery. The study would have benefited from a larger sample involving more woody species, but logistical constraints prevented this. Therefore, further research involving more than two savannah woody species and determining the concentrations of more leaf pigments and biochemicals other than chlorophyll, using a larger sample, would be beneficial. From the results it can be concluded that leaf area index (LAI) is the more reliable leaf characteristic for analysing the characteristics of savannahs in terms of leaf content. Therefore, algorithms that analyse LAI would be more useful than those determining chlorophyll content.

\section{References}

Asner, GP 1998, 'Biophysical and biochemical sources of variability in canopy reflectance', Remote Sensing of Environment, vol. 64, no. 3, pp. 234-253.

Baldini, E, Facini, O, Nerozzi, F, Rossi, F, \& Rotondi, A 1997, 'Leaf characteristics and optical properties of different woody species', Trees, vol. 12, no. 2, pp. 73-81.

Castro-Esau, KL, Sánchez-Azofeifa, GA, \& Caelli, T 2004, 'Discrimination of lianas and trees with leaflevel hyperspectral data', Remote Sensing of Environment, vol. 90, no. 3, pp. 353-372.

Ceccato, P, Flasse, S, Tarantola, S, Jacquemoud, S, \& Grégoire, JM 2001, 'Detecting vegetation leaf water content using reflectance in the optical domain', Remote Sensing of Environment, vol. 77, no. 1, pp. 2233.

Clark, B, Suomalainen, J, \& Pellikka, P 2010, 'A comparison of methods for the retrieval of surface reflectance factor from multitemporal SPOT HRV, HRVIR, and HRG multispectral satellite imagery', Canadian Journal of Remote Sensing, vol. 36. No. 4, pp. 397-411.

da Luz, BR, \& Crowley, JK 2007, 'Spectral reflectance and emissivity features of broad leaf plants: Prospects for remote sensing in the thermal infrared $(8.0-14.0 \mu \mathrm{m})$ ', Remote Sensing of Environment, vol. 109, no. 4, pp. 393-405. 
Eriksson, HM, Eklundh, L, Kuusk, A, \& Nilson, T 2006, 'Impact of understory vegetation on forest canopy reflectance and remotely sensed LAI estimates', Remote Sensing of Environment, vol. 103, no. 4, pp. 408418.

Gitelson, AA, Gritz, Y, \& Merzlyak, MN 2003, 'Relationships between leaf chlorophyll content and spectral reflectance and algorithms for non-destructive chlorophyll assessment in higher plant leaves', Journal of Plant Physiology, vol. 160, no. 3, pp. 271-282.

Grunow, JO 1980, 'Feed and habitat preferences among some large herbivores on African veld', Proceedings of the Annual Congresses of the Grassland Society of Southern Africa, vol. 15, no. 1, pp. 141-146.

Hempson, GP, Archibald, S, \& Bond, WJ 2015, 'A continent-wide assessment of the form and intensity of large mammal herbivory in Africa', Science, vol. 350, no. 6264, pp. 1056-1061.

Horler, DNH, Dockray, M., \& Barber, J 1983, 'The red edge of plant leaf reflectance', International Journal of Remote Sensing, vol. 4, no. 2, pp. 273-288.

Knipling, EB 1970, 'Physical and physiological basis for the reflectance of visible and near-infrared radiation from vegetation', Remote Sensing of Environment, vol.1, no. 3, pp. 155-159.

LI-COR Inc., 1992, LAI-2000 Plant Canopy Analyzer: Instruction Manual, LI-COR Inc., Lincoln, Nebraska, USA.

Lillesand, TM, Kiefer, RW, \& Chipman, JW, 2015, Remote Sensing and Image Interpretation, $7^{\text {th }}$ edition, Wiley, New York.

Mayr, MJ, \& Samimi, C 2015, 'Comparing the dry season in-situ Leaf Area Index (LAI) derived from highresolution Rapid Eye imagery with MODIS LAI in a Namibian Savanna', Remote Sensing, vol. 7, no. 4, pp. 4834-4857.

Mucina, L, \& Rutherford, MC, 2006, The vegetation of South Africa, Lesotho and Swaziland, Strelizia 19, South African National Biodiversity Institute, Pretoria, South Africa.

Munyati, C, Economon, EB, \& Malahlela, OE 2013, 'Effect of canopy cover and canopy background variables on spectral profiles of savanna rangeland bush encroachment species based on selected Acacia species (mellifera, tortilis, karroo) and Dichrostachys cinerea at Mokopane, South Africa', Journal of Arid Environments, vol. 94, pp. 121-126.

Peñuelas, J, Filella, I, Biel, C, Serrano, L, \& Save, R 1993, 'The reflectance at the 950-970 $\mathrm{nm}$ region as an indicator of plant water status', International Journal of Remote Sensing, vol. 14, no. 10, pp. 1887-1905.

Petisco, C, García-Criado, B, De Aldana, BV, Zabalgogeazcoa, I, \& Mediavilla, S 2005, 'Use of nearinfrared reflectance spectroscopy in predicting nitrogen, phosphorus and calcium contents in heterogeneous woody plant species', Analytical and Bioanalytical Chemistry, vol. 382, no. 2, pp. 458465.

Ribeiro, NS, Saatchi, SS, Shugart, HH, \& Washington-Allen, RA 2008, 'Aboveground biomass and leaf area index (LAI) mapping for Niassa Reserve, northern Mozambique', Journal of Geophysical Research: Biogeosciences, vol. 113, G02S02, doi:10.1029/2007JG000550.

Sánchez-Azofeifa, GA, Castro, K, Wright, SJ, Gamon, J, Kalacska, M, Rivard, B, Schnitzer, SA, \& Feng JL 2009, 'Differences in leaf traits, leaf internal structure, and spectral reflectance between two communities of lianas and trees: Implications for remote sensing in tropical environments', Remote Sensing of Environment, vol. 113, pp. 2076-2088.

Sims, DA, \& Gamon, JA 2002, 'Relationships between leaf pigment content and spectral reflectance across a wide range of species, leaf structures and developmental stages', Remote Sensing of Environment, vol. 81, no. 2-3, pp. 337-354.

Thiele, KR, Funk, VA, Iwatsuki, K, Morat, P, Peng, CI, Raven, PH, Sarukhán, J, \& Seberg, O 2011, 'The controversy over the retypification of Acacia Mill. with an Australian type: A pragmatic view', Taxon, vol. 60 , no. 1 , pp. 194-198. 